\title{
A Prospective Study to Examine the Association of the Foramen Ovale Size with Intraluminal Pressure of Pear-Shaped Balloon in Percutaneous Balloon Compression for Trigeminal Neuralgia
}

\author{
Qiao Wang · Cheng Chen · Gangwen Guo · Zhenxing Li • \\ Dong Huang $\cdot$ Haocheng Zhou (D)
}

Received: May 29, 2021 / Accepted: August 16, 2021 / Published online: August 30, 2021

(c) The Author(s) 2021

\begin{abstract}
Introduction: Percutaneous balloon compression (PBC) is an effective and safe option for patients with trigeminal neuralgia. A pearshaped balloon can be used to identify the proper compression of the Gasserian ganglion during the PBC procedure. The aim of this study was to evaluate the relationship between the foramen ovale (FO) size and intraluminal pressure of the pear-shaped balloon.

Methods: Thirteen patients that presented with classical trigeminal neuralgia were scheduled to undertake PBC surgery at the Pain Department of the Third Xiangya Hospital, Central South University, from November 2020 to April 2021.
\end{abstract}

Qiao Wang and Cheng Chen contributed equally to this paper.

Q. Wang · G. Guo · Z. Li · D. Huang $(\bowtie) \cdot$ H. Zhou $(\bowtie)$

Department of Pain, The Third Xiangya Hospital, Institute of Pain Medicine, Central South

University, Changsha, Hunan, China

e-mail: huangdong6619@vip.163.comH. Zhou

e-mail: haocheng.zhou@csu.edu.cn

\section{Chen}

Department of Radiology, The Third Xiangya

Hospital, Central South University, Changsha, China

D. Huang · H. Zhou

Hunan Key Laboratory of Brain Homeostasis,

Central South University, Changsha, China
Three-dimensional computed tomography reconstruction of the skull base was performed to capture the feature of FO preoperatively. The intraluminal pressure was continuously recorded when a pear-shaped balloon was obtained during the procedure. Correlation analysis was calculated to determine the association of the intraluminal balloon pressure with FO parameter.

Results: All participants reported complete relief of pain at discharge. The enduring analgesic effect of PBC was maintained in all patients with a median follow-up up to 5.5 months (range, 3-8 months). The average intraluminal balloon pressure was $161.5 \pm 29.4$ $\mathrm{kPa}$ at the initial compression (P1), and $134.8 \pm 21.5 \mathrm{kPa}$ at the ending of compression (P2), respectively. P1 was significantly correlated with the length $(r=0.61, P=0.024)$ of FO. Similarly, a significant and positive correlation was observed between P2 and the length $(r=0.63, P=0.022)$ of FO.

Conclusions: Preoperative assessment of FO may be a potential predictor of intraluminal pressure to reach a pear-shaped balloon during PBC treatment. Narrow FO is associated lower intraluminal balloon pressure.

Keywords: Trigeminal neuralgia; Percutaneous balloon compression; Foramen ovale; Intraluminal pressure; Pear-shaped balloon 


\section{Key Summary Points}

Why carry out this study?

Percutaneous balloon compression (PBC) is an effective therapy for patients with primary trigeminal neuralgia.

The key of $\mathrm{PBC}$ is to obtain a pear-like shaped balloon and proper intraluminal balloon pressure.

Over-compression is associated with a greater risk of complications, however, insufficient intraluminal pressure may contribute to the failure of surgery. Can we predict the target pressure during $\mathrm{PBC}$ when a pear-shaped balloon appears?

What was learned from the study?

Narrow foramen ovale was correlated with lower intraluminal pressure when a pearshaped balloon was obtained.

Preoperative assessment of the foramen ovale may be useful in predicting the intraluminal pressure during PBC.

\section{INTRODUCTION}

Trigeminal neuralgia (TN) is a debilitating facial pain syndrome characterized by sudden usually unilateral severe, brief, stabbing, recurrent episodes of pain in one or more dermatomes of the fifth cranial nerve [1]. It has been estimated that the prevalence of TN ranges from 0.03 to $0.3 \%$ $[2,3]$. Carbamazepine remains the first-line medication for initial pain management of TN. However, the therapeutic effect of medication may decrease over time, even with increasing doses and/or additional analgesic agents [4]. Invasive procedures may be considered when TN patients cannot control pain with conservative therapy. About $75 \%$ of TN patients ultimately chose surgical intervention to treat trigeminal pain [5].
Microvascular decompression (MVD) is the most applied procedure for TN population. Although immediate postoperative pain relief was complete in $82 \%$ cases, the annual risk of recurrence ranged from $2-5 \%$ five years after surgery [6]. For recurrence of TN, percutaneous balloon compression (PBC) may be an alternative option for those underwent MVD or other destructive neurosurgical techniques (e.g., gamma knife, radiofrequency, and glycerol rhizotomy) [7].

It is well accepted that the appearance of a pear-like shaped balloon during PBC procedure is the key factor of surgery [7-10]. With a lateral view of the skull, physicians can confirm the balloon's position and adequate compression during operation [9]. However, the air-fluid level in the balloon may hinder effective compression $[10,11]$. As a result, the patient may still present severe pain and require further treatment after surgery. Conversely, postoperative cranial nerve deficits were associated with over-compression, which was reported in $1.5 \%$ of patients after PBC $[12,13]$. To achieve pain relief with minimal sensory deficit, the intraluminal balloon pressure can be monitored to determine the proper tissue compression $[14,15]$.

Despite a different procedural kit, the target intraluminal pressure ranged from 1.3 to $1.6 \mathrm{~atm}$ across studies [14-17]. Consistent with the guidance of the pear-shaped balloon, the initial intraluminal pressure was significantly higher when the balloon was positioned properly inside the Meckel's cave than those outside the Meckel's cave or into the posterior fossa [15]. However, intraluminal balloon pressure monitoring is not routinely performed by neurosurgeons, and the pear shape may not always appear [18]. Previous anatomical evidence has demonstrated that the size of foramen ovale (FO) is correlated with the pathogenesis of TN [19-21]. In addition, it is necessary to perform the reconstruction of the FO to achieve correct cannulation during PBC surgery [22]. However, the relationship between the size of FO and intraluminal balloon pressure remains unclear.

Therefore, in this study we aimed to capture the features of FO with high-resolution CT to examine its relationship with intraluminal 
pressure of a pear-shaped balloon in a PBC procedure.

\section{METHODS}

\section{Study Design and Participants Population}

The A Prospective Study to Examine the Association of the Foramen Ovale Size with Intraluminal Pressure of Pear-Shaped Balloon in Percutaneous Balloon Compression for Trigeminal Neuralgia was designed to examine the relationship between the size of FO and intraluminal pressure of a pear-shaped balloon during a $\mathrm{PBC}$ procedure. From November 2020 to April 2021, we enrolled 13 TN patients at the Pain Department of The Third Xiangya Hospital, Central South University, Changsha, China. All patients were diagnosed with primary TN (TN type 1 ), with one or more trigeminal branches affected. In addition to a clinical diagnosis of $\mathrm{TN}$, all patients were not treated with any other surgical intervention such as MVD, radiofrequency thermocoagulation to avoid potential bias. The flow chart of participant selection is shown in Fig. 1. The study was conducted in accordance with the Declaration of Helsinki and approved by the

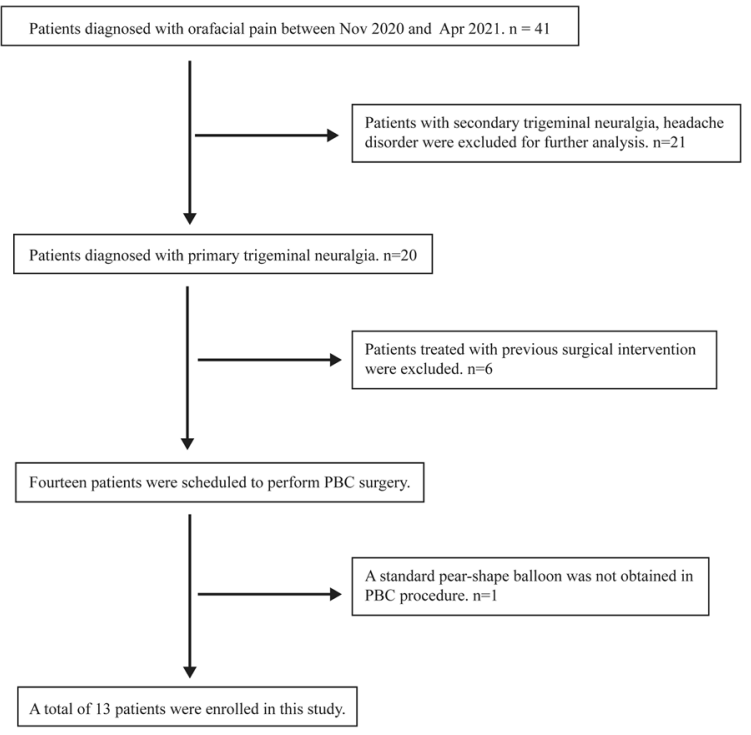

Fig. 1 The flow chart of patient selection
Ethics Committee of The Third Xiangya Hospital, Central South University (\#21027). Written consent was acquired from all participates in this study. The study was registered at chictr.org.cn (ChiCTR2100046203).

\section{Measurement of Foramen Parameter}

Three-dimensional computed tomography reconstruction of the skull base was performed on a 64-detector row scanner (Philips) or equivalent for all patients in this study (Fig. 2a, b). Helical images were acquired in a plane parallel to the infraorbitomeatal line with $0.625 \mathrm{~mm}$ detector width, $120 \mathrm{kVp}$, and 200 $\mathrm{mAs}$. The data were transferred to the imaging workstation (Philips) for the reconstruction of FO. The dimension of FO was calculated with an imaging viewing tool (Philips) by two independent reviewers (Q.W. and C.C.). Measurement of FO is shown in Fig. 2.

\section{Surgical Techniques}

The surgical detail of PBC was initially reported by Mullan and Lichtor [10]. Briefly, the patient was placed in supine position with the neck slightly extended to achieve better visualization of the FO. General anesthesia with intubation was performed to ensure the hemodynamic stability during the procedure. A 14-gauge needle with stylet (CTZ-14; Qingyuan, Shenzhen, China) was inserted $2.5-3 \mathrm{~cm}$ lateral to the angle of the mouth. The needle was advanced gradually into the FO under the guidance of C-arm fluoroscopy (TOSHIBA), as shown in Fig. 3. The stylet was then removed, and a $4 \mathrm{~F}$ Fogarty balloon catheter (QK08S50; Qingyuan, Shenzhen, China) was inserted less than $2 \mathrm{~cm}$ beyond the tip of the needle. One electrical pressure transducer (BPI-01; Qingyuan, Shenzhen, China) was connected to the Fogarty balloon catheter for the recording of intraluminal pressure. Before the balloon inflation, we can check the pressure in vitro with different volume of contrast (Fig. 4). About $0.4-0.8 \mathrm{ml}$ of iohexol at a concentration of $120 \mathrm{mg} / \mathrm{ml}$ was injected to inflate the balloon to achieve a standard shape of a pear (Fig. 3c). The 


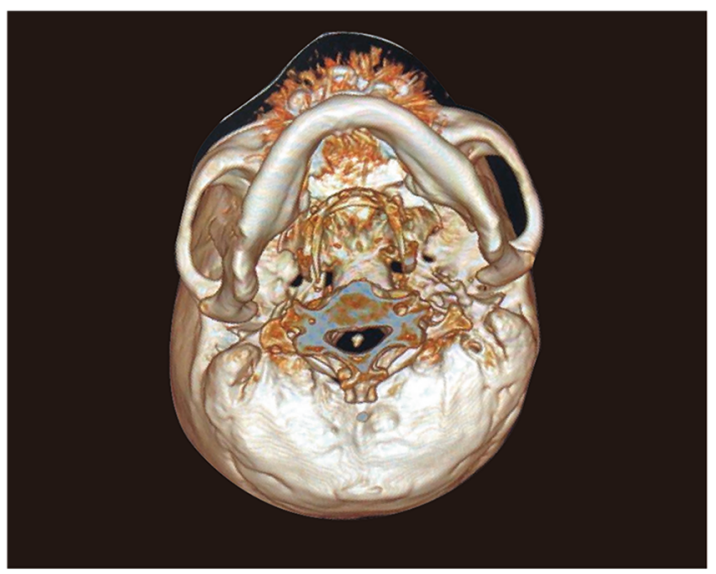

(a)

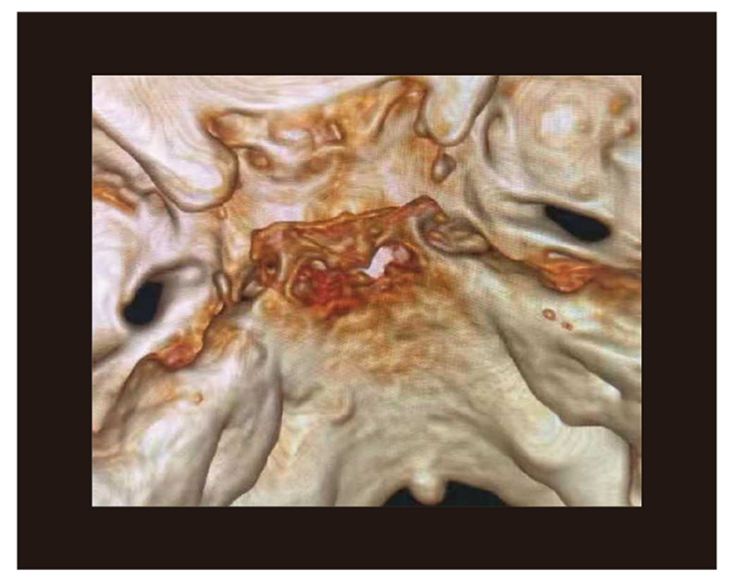

(b)

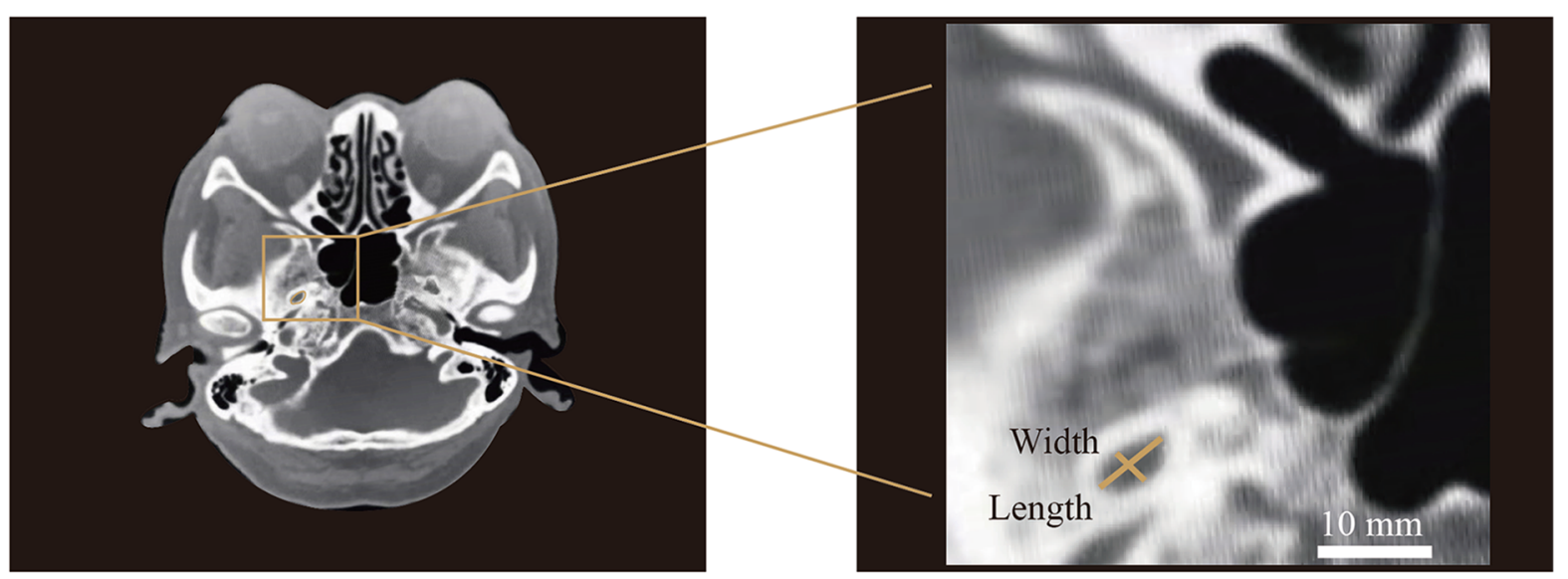

(c)

(d)

Fig. 2 Measurement of FO parameter. a Three-dimensional reconstruction of the skull base by high definition of computed tomography. $\mathbf{b}$ The antapical view of FO. $\mathbf{c}$ The transverse section of FO. $\mathbf{d}$ The width and length of FO (scale bar $10 \mathrm{~mm}$ )

compression was held for $120 \mathrm{~s}$ before the contrast was extracted, and then the needle and catheter were removed.

\section{Therapeutic Assessment and Follow-ups}

The therapeutic effect of PBC was evaluated by the Barrow Neurological Institute (BNI) criteria [23]. The detail of BNI scoring system is given in Table 1. One simplification of the BNI questionnaire was used for better illustration of data in this study [24]. Specifically, BNI grades of I-III were classified as effective relief from TN.
BNI grades IV and V indicates insufficient pain relief [24]. One telephone interview was conducted routinely 1,3 , and 6 months after PBC procedure.

\section{Statistical Analysis}

The information of the patients was collected with one standard questionnaire. Descriptive analysis was applied to capture the demographic features of the participants. The quantitative variables are presented as the mean \pm standard deviation. The Shapiro-Wilk 


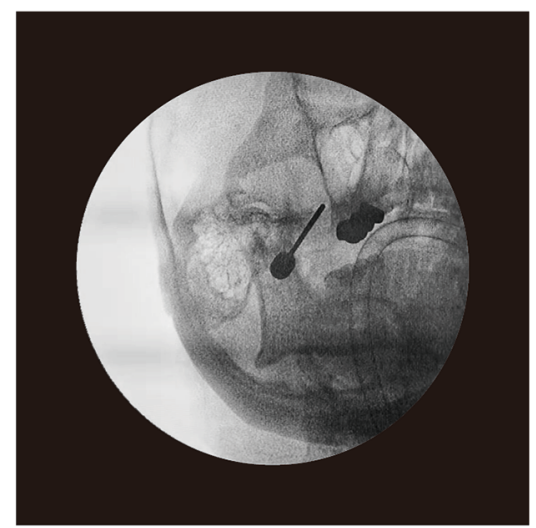

(a)

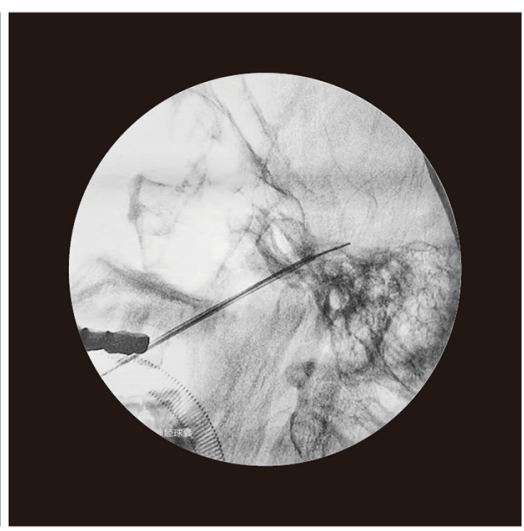

(b)

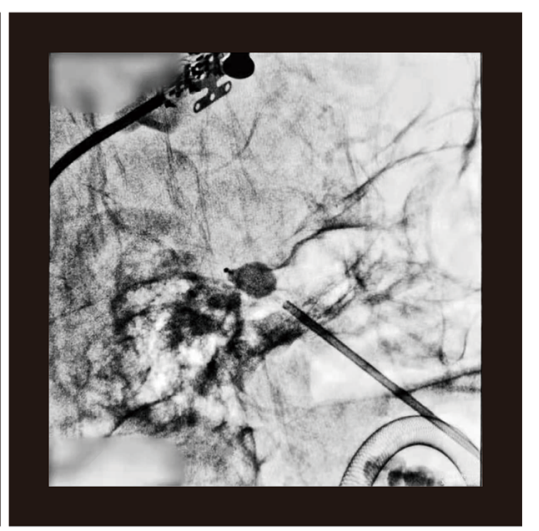

(c)

Fig. 3 Placement of the balloon identified by the fluoroscopic imaging. a Anterior-posterior view of the cannulation of FO. b Location of the Fogarty balloon

catheter at the lateral view before compression. c A standard pear-shaped balloon obtained during the surgery

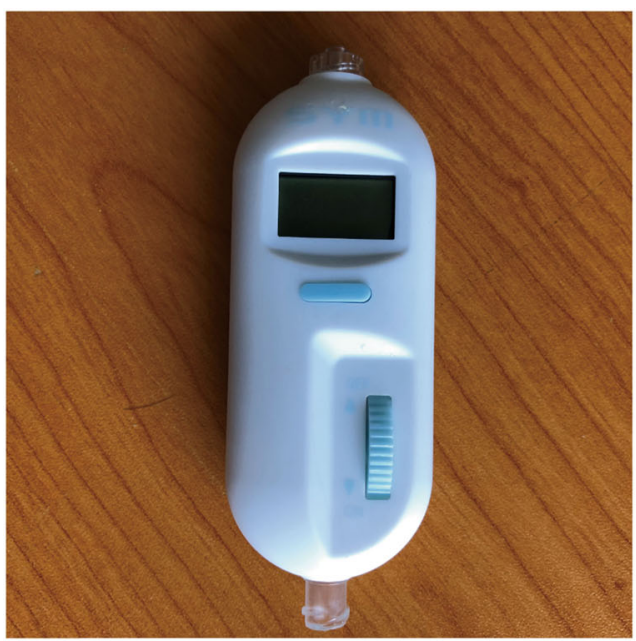

(a)

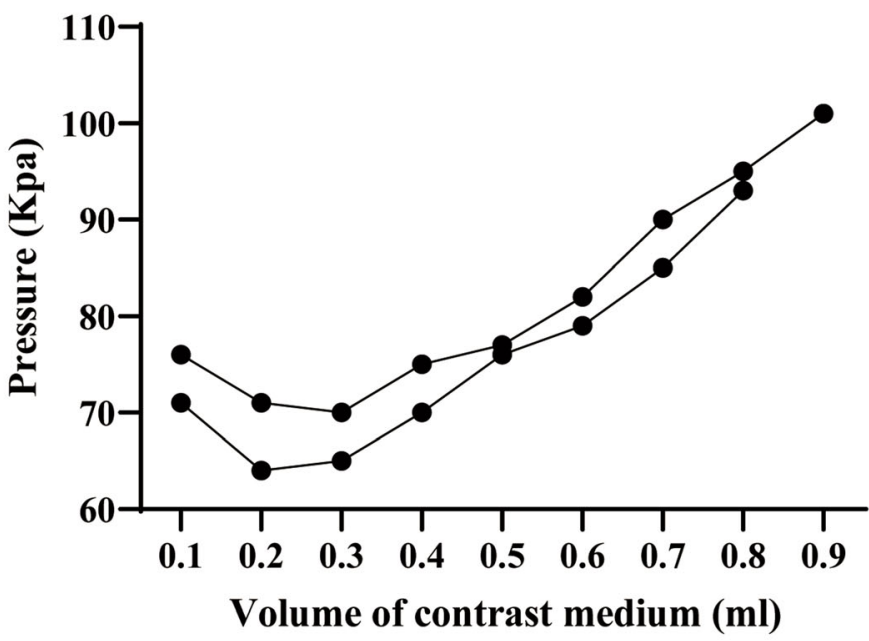

(b)

Fig. 4 Measurement of the intraluminal balloon pressure. a The mini electronical pressure transducer for intraluminal balloon pressure recording. $\mathbf{b}$ The effect of contrast volume on the intraluminal balloon pressure in vitro

test was performed to measure the normality value of each variable. Pearson correlation coefficient was performed for variables with normal distribution. Spearman's correlation test was applied on abnormal distribution value. $P$ value $<0.05$ was considered statistically significant. Data analysis was performed with Prism v8 (GraphPad, San Diego, CA, USA).

\section{RESULTS}

\section{General Demographics}

A total of 13 patients diagnosed with $\mathrm{TN}$ were enrolled in this study, with a mean age of $66 \pm 13$ years old. Most of the participants (eight out of 13) were females. The axillary (V2) 
Table 1 Barrow Neurological Institute (BNI) pain severity scoring system

\begin{tabular}{ll}
\hline Score & \\
\hline I & No trigeminal pain, no medication \\
II & Occasional pain, not requiring medication \\
II & Some pain, adequately controlled with medication \\
IV & $\begin{array}{c}\text { Some pain, not adequately controlled with } \\
\end{array}$ \\
& medication \\
V & Serve pain/no pain relief \\
\hline
\end{tabular}

and mandibular (V3) were mostly affected in this study. All patients presented with severe facial pain with baseline visual analogue scores of $7.0 \pm 1.0$. In this study, 12 of 13 patients were treated with carbamazepine, and one patient took oxcarbazepine after the carbamazepine lost its effectiveness. The last patient took gabapentin instead of oxcarbazepine or carbamazepine for drug-related liver damage. The general demographic data is given in the Table 2.

\section{Clinical Outcome and Follow-ups}

We conducted one routine follow-up for the patients 1, 3, and 6 months after PBC therapy. The duration of last follow-up ranged from 3 to 8 months, with a median time of 5.5 months. Twelve of 13 participants reported being total pain free immediately after surgery (BNI grade I), only one patient felt occasional pain and the pain was completely relieved before discharge and at the 1- and 3-month follow-up. At the 3-month follow-up, one patient experienced mild recurrent pain that was well controlled by carbamazepine ( $0.1 \mathrm{~g}$ once per night). Seven out of 13 patients completed the 6-month followup and were rated as BNI grade I. The clinical outcome collected at each time point is shown in Table 3.
Table 2 General characteristics of patients that underwent percutaneous balloon compression

\begin{tabular}{|c|c|}
\hline \multicolumn{2}{|l|}{ Characteristics } \\
\hline Age (mean \pm standard deviation, years) & $66 \pm 13$ \\
\hline Sex (male/female) & $5: 8$ \\
\hline Disease duration (median, range, months) & $60(2-240)$ \\
\hline Affected side (left/right) & $9 / 4$ \\
\hline \multicolumn{2}{|l|}{ Affected branch $(n, \%)$} \\
\hline $\mathrm{V} 1$ & $5(23.8)$ \\
\hline V2 & $8(38.1)$ \\
\hline V3 & $8(38.1)$ \\
\hline \multicolumn{2}{|l|}{ Number of affected branches $(n, \%)$} \\
\hline 1 & $7(53.8)$ \\
\hline 2 & $4(30.8)$ \\
\hline 3 & $2(15.4)$ \\
\hline \multicolumn{2}{|l|}{ Preoperative pain severity } \\
\hline VAS (mean \pm standard deviation) & $7 \pm 1$ \\
\hline BNI grade I-III & 0 \\
\hline BNI grade IV & 3 \\
\hline BNI grade $\mathrm{V}$ & 10 \\
\hline \multicolumn{2}{|l|}{ Previous medication $(n, \%)$} \\
\hline Carbamazepine & $12(92.3)$ \\
\hline Oxcarbazepine & $1(7.7)$ \\
\hline Gabapentin & $1(7.7)$ \\
\hline Follow-up time (median, range, months) & $5.5(3.0-8.0)$ \\
\hline
\end{tabular}

VAS Visual Analog Scale, BNI Barrow Neurological Institute

\section{Intraluminal Balloon Pressure Recording}

To examine the effect of contrast volume, the intraluminal pressure in vitro was recorded continuously with an electronical pressure transducer (Fig. 4). The two connecting lines in Fig. 4b indicated two trails of pressure recording performed by two independent researchers (H.Z. and Q.W.). The opening pressure (P1) increased around $70-75 \mathrm{kPa}$ rapidly with $0.1 \mathrm{ml}$ 
Table 3 Assessment of pain relief at each time point

\begin{tabular}{lcllll}
\hline & Baseline & Initial relief & $\mathbf{1}$ month & $\mathbf{3}$ months & Last follow-up \\
\hline BNI grades I-III & 0 & 13 & 13 & 13 & 13 \\
BNI grades IV and V & 13 & 0 & 0 & 0 & 0 \\
\hline
\end{tabular}

BNI Barrow Neurological Institute

contrast inflated. The pressure gradually dropped to a lower level after $0.3 \mathrm{ml}$ contrast was injected. The volume of contrast we applied during the PBC surgery ranged between 0.4 and $0.8 \mathrm{ml}$, in which the intraluminal increased with contrast volume. The change of intraluminal balloon pressure with different contrast volume in vitro is given in Fig. 4 .

\section{Correlation Between Intraluminal Pressure and Foramen Parameter}

In Fig. 5, we present the correlations of intraluminal balloon pressure with the width, length, aspect ratio, and square of FO. Correlation analysis demonstrated that the length of FO was significantly and strongly associated with the initial intraluminal balloon pressure $(r=0.61, P=0.024)$. Similarly, the intraluminal pressure after compression (P2) was also significantly and positively associated with the length of FO $(r=0.63, P=0.022)$, as shown in Fig. 6. Given the abnormal distribution, we performed the Spearman's correlation test to evaluate the relationship between the square of FO and the intraluminal pressure. Neither P1 nor P2 showed significant correlations with the width, aspect ratio, and square of FO.

\section{DISCUSSION}

PBC is an effective and safe procedure option for TN patients who refuse to undergo open surgery or recurrence after MVD. Valid compression of the trigeminal ganglion and nerve root is the key factor of PBC surgery, which can be judged by the intraluminal balloon pressure and shape of balloon. Here, we examined the relationship between the intraluminal pressure of pear- shaped balloon and FO size. We found that the size of FO was significantly associated with the intraluminal balloon pressure, a narrower FO indicated lower intraluminal pressure of pearshaped balloon during the PBC procedure.

Carbamazepine remains the first-line therapy after initial diagnosis of TN. Even when TN patients increase the dose of carbamazepine, the analgesic effect may still decrease over time [4]. Invasive intervention may be considered if conservative therapy cannot provide sufficient control of pain. After separation of tangled vessels and trigeminal nerve, the MVD technique has been reported to achieve a considerable success rate for TN population [25]. However, many patients may refuse the open surgery and the surgery-related mortality rate was about $0.37 \%$ [26]. In addition, patients may present with recurrent pain due to vessel compression, Teflon compression, or granuloma and arachnoid adhesion [27].

To reduce the risk of severe complications, percutaneous minimally invasive method is commonly performed to treat $\mathrm{TN}$. It has been demonstrated that PBC is an effective and safe option for the elderly population [28]. The other advantage of $\mathrm{PBC}$ is the considerable high success rate for recurrence TN after PBC or other unsuccessful treatment [29]. However, we excluded the participants who were treated with previous MVD or destructive trigeminal surgery to avoid the potential bias in this study. Consistent with previous data, a pear-shaped balloon, which indicates the correct compression applied to the Meckel's cave, is an important predictor of successful clinical outcome [8]. As a result, all patients in this study reported complete relief from pain before discharge.

Neurological physicians can confirm the location of compression by the balloon shape. Also, a properly positioned balloon had greater 


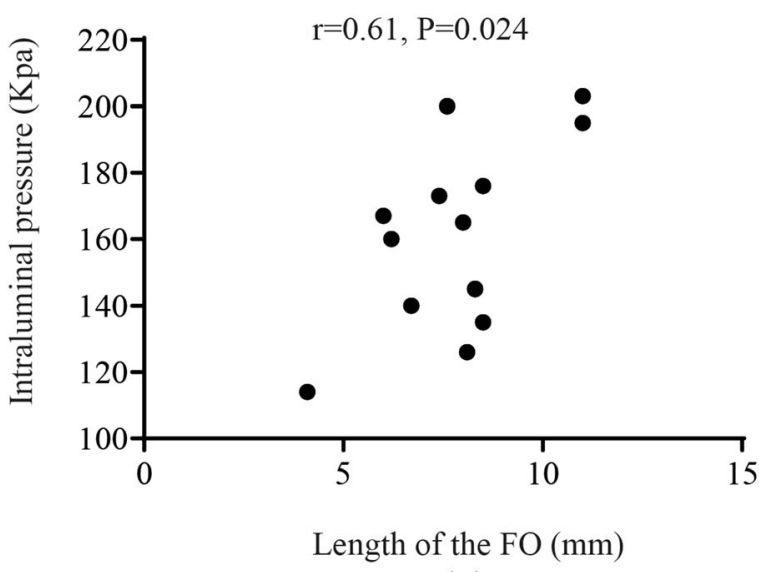

(a)

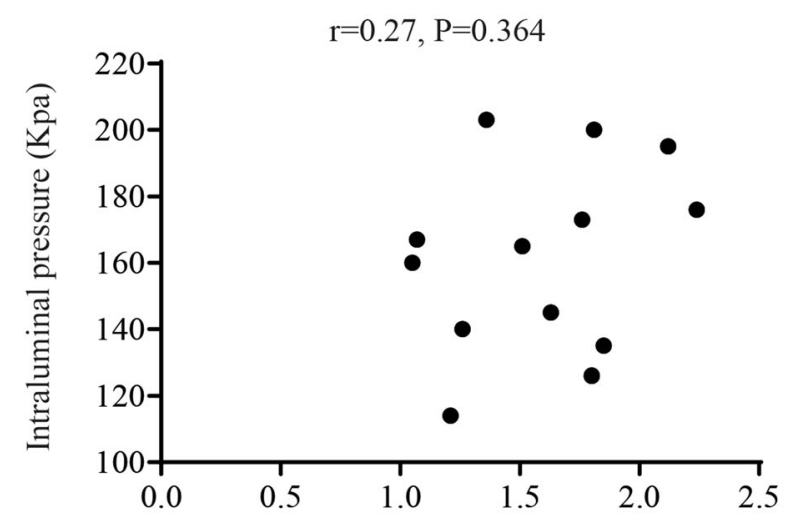

Aspect ratio of the FO

(c)

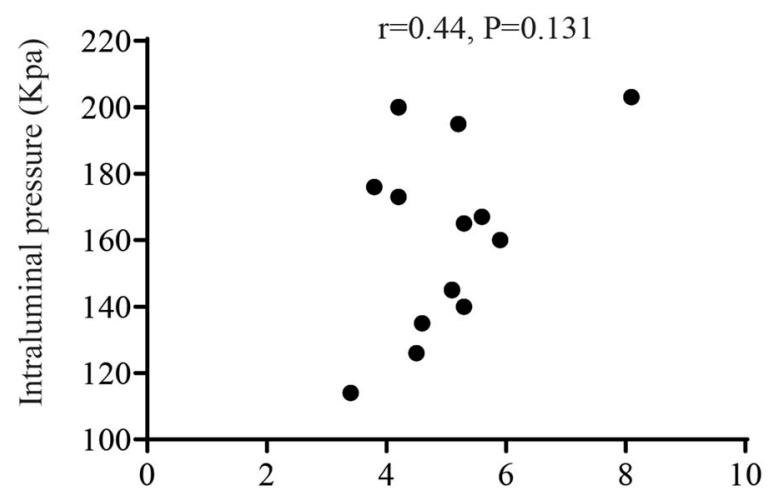

Width of the FO (mm)

(b)

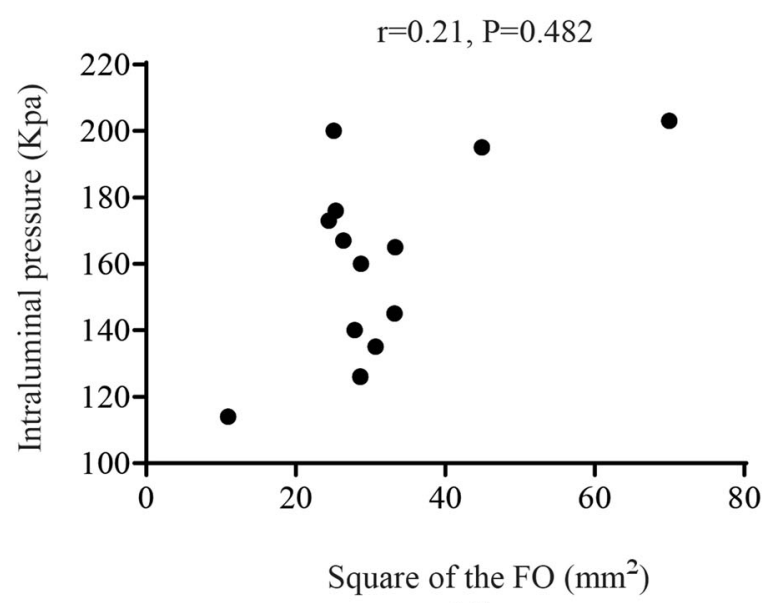

(d)

Fig. 5 Relationship between the initial compression pressure (P1) and the FO length (a), width (b), aspect ratio (c), and square (d)

intraluminal pressure due to the resistance from stretching of the dura around Meckel's cave [15]. The target intraluminal balloon pressure at initial compression ranged from 1065 to $1215 \mathrm{mmHg}[14,15]$. Likely, we found that the average intraluminal balloon pressure was $161.5 \pm 29.4 \mathrm{kPa}(1211 \pm 220 \mathrm{mmHg})$ at the initial compression. However, the individual pressure was dramatically variable. In this study, the maximal intraluminal balloon pressure $(203 \mathrm{kPa})$ was almost twice higher than the lowest one, both of whom achieved standard pear-shaped balloon during the surgery. Thus, it is necessary to perform the individualized compression pressure monitoring for $\mathrm{PBC}$ procedure.

Despite the balloon shape, the cannulation of FO is also important for PBC and the diversity of the FO shape may contribute to the operative difficulties [29]. To facilitate the cannulation, the reconstruction of the FO is useful with CT navigation perioperatively. In this study, we recorded the parameter of FO and examined its relationship with the intraluminal balloon pressure. Greater width and length of the FO was found in this study when compared with previous data [19]. The range of width was $4.1-11.0 \mathrm{~mm}$, and $3.4-8.1 \mathrm{~mm}$ for length of the 


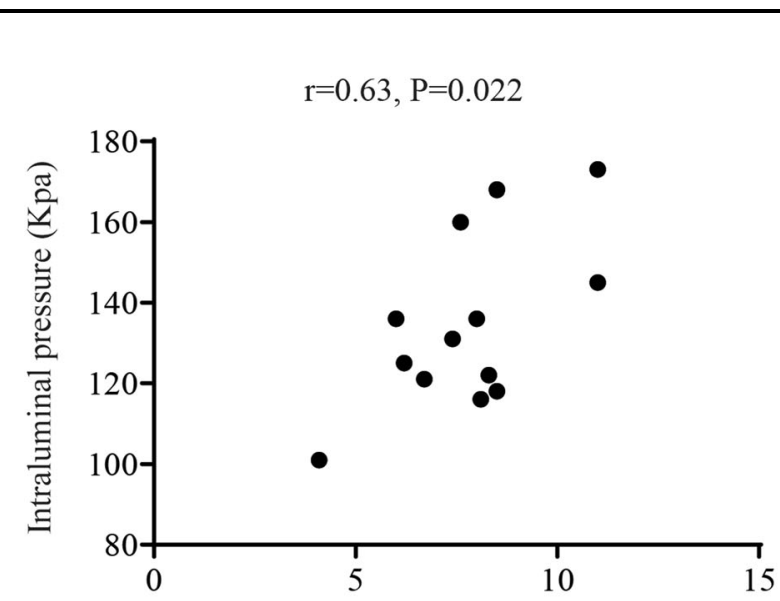

Length of the FO (mm)

(a)

$\mathrm{r}=0.37, \mathrm{P}=0.219$

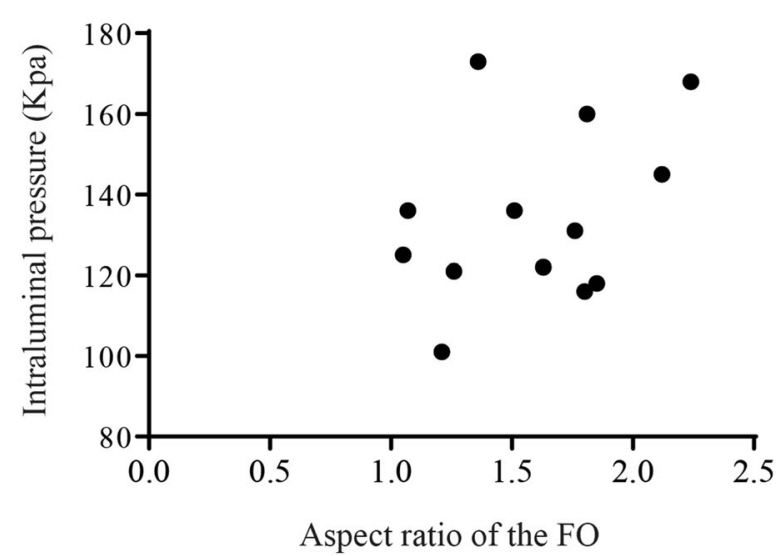

(c)

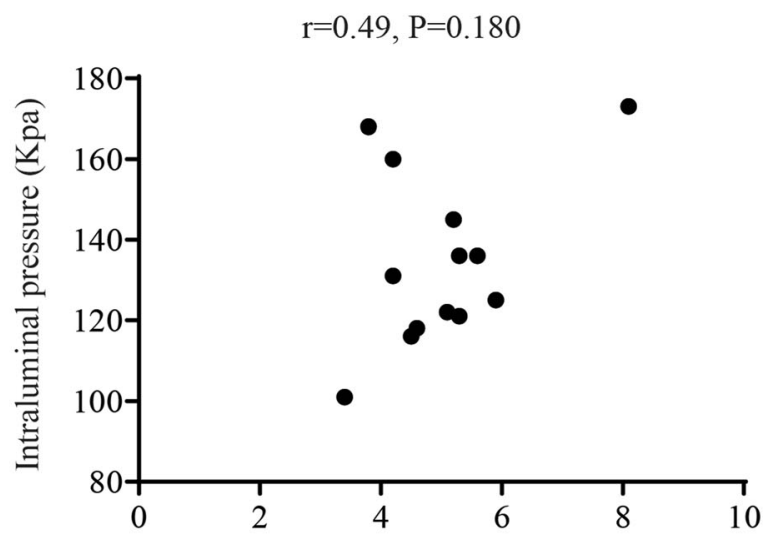

Width of the FO (mm)

(b)

$\mathrm{r}=0.26, \mathrm{P}=0.394$

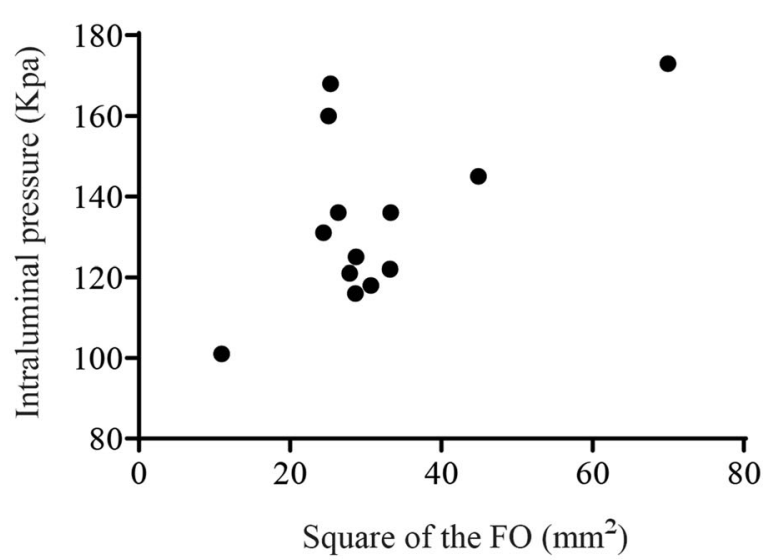

(d)

Fig. 6 Relationship between the ending compression pressure (P2) and the FO length (a), width (b), aspect ratio (c), and square (d)

FO respectively. However, the aspect ratio was similar to the number reported by Liu et al. [19].

Anatomical studies have revealed the association of the size of FO with TN, and narrower FO may be correlated with higher risk of TN [19-21]. Our study focused, for the first time, on the relationship between the FO size and intraluminal balloon pressure in PBC surgery. When a pear-shaped balloon appeared, both initial and ending compression pressures were significantly and positively correlated with the length of FO. Our finding indicates a potential predictor of intraluminal pressure target, which can be performed by the preoperative three-dimensional reconstruction of FO. Combined with the intraluminal pressure monitoring system, the individualized assessment of the FO may help reduce the incidence of complications caused by over compression [12-14].

To obtain one pear-shaped balloon, the needle should be placed close to the posterior rim of foramen ovale, demonstrated by the lateral view of fluoroscopy (Fig. 3b). Meanwhile, the needle should be placed close to the middle 
or medial end of foramen to ensure that the needle enters the Meckel's cave, which can be confirmed by the anteroposterior view of fluoroscopy (Fig. 3a). Thus, the angle of needle insertion should be further off the sagittal plane to target the middle or medial end of foramen. As a result, the balloon approaches close to the medial bony side of the Meckel's cave, which in turn induces a higher intraluminal pressure by mechanical compression. Thus, we pressume that the angular factor of cannulation may contribute to the changes of intraluminal balloon pressure across different size of foramen ovale.

Our study has several limitations. First of all, the main limitation is the observational nature of study design. Second, we excluded the participants who did not obtain a standard pearshaped balloon in the surgery. The effect of balloon shape on the intraluminal pressure needs to be further confirmed in a future study. Third, the number of samples is relatively limited. Finally, the duration of follow-ups was relatively short. The effect of intraluminal pressure on long-term recurrence rate and complications should be examined in the future.

\section{CONCLUSIONS}

Taken together, preoperative assessment of FO may be a potential predictor of intraluminal pressure to reach a pear-shaped balloon during PBC. Narrow FO is associated with lower intraluminal balloon pressure.

\section{ACKNOWLEDGEMENTS}

The authors would like to thank the participants of the study.

Funding. This research was funded by National Natural Science Foundation of China, (81901146 to H.Z. and 81771101 to H.Z. and D.H.), the Key Laboratory of Hunan Province grants (2018TP1009 to H.Z. and D.H.), and the Huizhiyucai Project of the Third Xiangya
Hospital, Central South University. The journal's Rapid Service Fee was funded by the authors.

Authorship. All named authors meet the International Committee of Medical Journal Editors (ICMJE) criteria for authorship for this article, take responsibility for the integrity of the work as a whole, and have given their approval for this version to be published.

Authors' Contributions. Qiao Wang and Cheng Chen contributed equally to this paper. Haocheng Zhou and Dong Huang contributed to the study conception and design. Material preparation, data collection, and analysis were performed by Qiao Wang, Cheng Chen, Zhenxing Li, Gangwen Guo, Dong Huang, and Haocheng Zhou. The first draft of the manuscript was written by Haocheng Zhou and all authors commented on previous versions of the manuscript. All authors read and approved the final manuscript.

Disclosure. Qiao Wang, Cheng Chen, Gangwen Guo, Zhenxing Li, Dong Huang, and Haocheng Zhou declare that they have no conflicts of interest.

Compliance with Ethics Guidelines. The study was conducted in accordance with the Declaration of Helsinki and approved by the Ethics Committee of The Third Xiangya Hospital, Central South University (\#21027). Written consent was acquired from all participates in this study. The study was registered at chictr.org.cn (ChiCTR2100046203).

Data Availability. The datasets generated during and/or analyzed during the current study are available from the corresponding author on reasonable request.

Open Access. This article is licensed under a Creative Commons Attribution-NonCommercial 4.0 International License, which permits any non-commercial use, sharing, adaptation, distribution and reproduction in any medium or format, as long as you give appropriate credit to the original author(s) and the source, provide 
a link to the Creative Commons licence, and indicate if changes were made. The images or other third party material in this article are included in the article's Creative Commons licence, unless indicated otherwise in a credit line to the material. If material is not included in the article's Creative Commons licence and your intended use is not permitted by statutory regulation or exceeds the permitted use, you will need to obtain permission directly from the copyright holder. To view a copy of this licence, visit http://creativecommons.org/licenses/by$\mathrm{nc} / 4.0 /$.

\section{REFERENCES}

1. Merskey H, Bogduk N. Classification of chronic pain. Descriptors of chronic pain syndromes and definitions of pain terms. 2nd ed. Seattle: IASP Press; 1994.

2. Mueller D, Obermann M, Yoon MS, Poitz F, Hansen N, Slomke MA, Dommes P, Gizewski E, Diener HC, Katsarava Z. Prevalence of trigeminal neuralgia and persistent idiopathic facial pain: a population-based study. Cephalalgia. 2011;31(15):1542-8.

3. De Toledo IP, Conti Réus J, Fernandes M, Porporatti AL, Peres MA, Takaschima A, Linhares MN, Guerra E, De Luca CG. Prevalence of trigeminal neuralgia: a systematic review. J Am Dent Assoc. 2016;147(7): 570-576.e2.

4. Zakrzewska JM, Linskey ME. Trigeminal neuralgia. BMJ Clin Evid. 2014;2014:1207.

5. Broggi G, Ferroli P, Franzini A. Treatment strategy for trigeminal neuralgia: a thirty years experience. Neurol Sci. 2008;29(Suppl 1):S79-82.

6. Barker FG 2nd, Jannetta PJ, Bissonette DJ, Larkins $\mathrm{MV}$, Jho HD. The long-term outcome of microvascular decompression for trigeminal neuralgia. N Engl J Med. 1996;334(17):1077-83.

7. Montano N, Papacci F, Cioni B, Di Bonaventura R, Meglio M. The role of percutaneous balloon compression in the treatment of trigeminal neuralgia recurring after other surgical procedures. Acta Neurol Belg. 2014;114(1):59-64.

8. Asplund P, Linderoth B, Bergenheim AT. The predictive power of balloon shape and change of sensory functions on outcome of percutaneous balloon compression for trigeminal neuralgia. J Neurosurg. 2010;113(3):498-507.

9. Gerber AM. Percutaneous trigeminal nerve compression for treatment of trigeminal neuralgia: results in 50 patients. Neurosurgery. 1993;33(5): 947-8.

10. Mullan S, Lichtor T. Percutaneous microcompression of the trigeminal ganglion for trigeminal neuralgia. J Neurosurg. 1983;59:1007-12.

11. Belber CJ, Rak RA. Balloon compression rhizolysis in the surgical management of trigeminal neuralgia. Neurosurgery. 1987;20:908-13.

12. Lobato RD, Rivas JJ, Sarabia R, et al. Percutaneous microcompression of the Gasserian ganglion for trigeminal neuralgia. J Neurosurg. 1990;72:546-53.

13. Lopez BC, Hamlyn PJ, Zakrzewska JM. Systematic review of ablative neurosurgical techniques for the treatment of trigeminal neuralgia. Neurosurgery. 2004;54:973-83.

14. Brown JA, Pilitsis JG. Percutaneous balloon compression for the treatment of trigeminal neuralgia: results in 56 patients based on balloon compression pressure monitoring. Neurosurg Focus. 2005;18(5): E10.

15. Lee ST, Chen JF. Percutaneous trigeminal ganglion balloon compression for treatment of trigeminal neuralgia-part I: pressure recordings. Surg Neurol. 2003;59(1):63-6 (discussion 66-67).

16. Brown JA. Percutaneous balloon compression for trigeminal neuralgia. Clin Neurosurg. 2009;56: $73-8$.

17. Brown JA, Chittum CJ, Sabol D, Gouda JJ. Percutaneous balloon compression of the trigeminal nerve for treatment of trigeminal neuralgia. Neurosurg Focus. 1996;1(2):e4 (discussion $1 \mathbf{p}$ following e4).

18. Brown JA, Pilitsis JG. Balloon compression for trigeminal neuralgia. In: Lozano AM, Gildenberg PL, Tasker RR, editors. Textbook of stereotactic and functional neurosurgery. Berlin: Springer; 2009.

19. Liu P, Zhong W, Liao C, Liu M, Zhang W. Narrow foramen ovale and rotundum: a role in the etiology of trigeminal neuralgia. J Craniofac Surg. 2016;27(8):2168-70.

20. Neto HS, Camilli JA, Marques MJ. Trigeminal neuralgia is caused by maxillary and mandibular nerve entrapment: greater incidence of right-sided facial symptoms is due to the foramen rotundum and foramen ovale being narrower on the right side of the cranium. Med Hypotheses. 2005;65(6):1179-82. 
21. Liang L, Diao Y, Xu Q, Zhang M. Transcranial segment of the trigeminal nerve: macro-/microscopic anatomical study using sheet plastination. Acta Neurochir. 2014;156(3):605-12.

22. Xiaochuan $H$, Xiaoyun S, Junsheng L, Ning G, Wenshi G, Zhenxing Z. Percutaneous microballoon compression for trigeminal neuralgia using DynaCT. Interv Neuroradiol. 2013;19(3):359-64.

23. Rogers CL, Shetter AG, Fiedler JA, Smith KA, Han $\mathrm{PP}$, Speiser BL. Gamma knife radiosurgery for trigeminal neuralgia: the initial experience of The Barrow Neurological Institute. Int J Radiat Oncol Biol Phys. 2000;47(4):1013-9.

24. Liu M, Tang S, Li T, Xu Z, Li S, Zhou Y, Li L, Wang W, Shi J, Shi W. Prognostic nomogram for percutaneous balloon compression in the treatment of trigeminal neuralgia. Neurosurg Rev. 2021. https:// doi.org/10.1007/s10143-021-01514-4.

25. Wang $X$, Wang $H$, Chen $S$, Liang $H$, Wang $H, X u M$, $\mathrm{Xu}$ L. The long-term clinical outcomes of microvascular decompression for treatment of trigeminal neuralgia compressed by the vertebrabasilar artery: a case series review. BMC Neurol. 2019;19(1):217.

26. Tatli M, Satici O, Kanpolat Y, Sindou M. Various surgical modalities for trigeminal neuralgia: literature study of respective long-term outcomes. Acta Neurochir. 2008;150(3):243-55.

27. Liu J, Wu G, Xiang H, Liu R, Li F, Hei B, Qian W, Song H, Liu Z. Long-term retrospective analysis of microvascular decompression in patients with recurrent trigeminal neuralgia. Front Neurol. 2020;11:584224.

28. Du YF, Gu Q, Yang DB, et al. Percutaneous balloon compression for primary trigeminal neuralgia in patients older than 80 years. Chin Neurosurg J. 2015;1:8

29. Zdilla MJ, Hatfield SA, Mangus KR. Angular relationship between the foramen ovale and the trigeminal impression: percutaneous cannulation trajectories for trigeminal neuralgia. J Craniofac Surg. 2016;27(8):2177-80. 